\title{
Furan production from glycoaldehyde over HZSM-5
}

\author{
Seonah Kim ${ }^{\mathrm{a}^{*}}$, Tabitha J. Evans ${ }^{\mathrm{a}}$, Calvin Mukarakate ${ }^{\mathrm{a}}$, Lintao Bü, Gregg T. Beckhamª Mark R. Nimlos ${ }^{\mathrm{a}}$, Robert S. \\ Paton $^{\mathrm{b}}$ and David J. Robichaud ${ }^{\mathrm{a}^{*}}$ \\ a National Bioenergy Center, National Renewable Energy Laboratory, 15013 Denver West Pkwy, Golden, CO, 80401 \\ ${ }^{\mathrm{b}}$ Chemistry Research Laboratory, University of Oxford, Oxford OX1 3TA, United Kingdom \\ *seonah.kim@nrel.gov, 303-384-7323 \\ *david.robichaud@nrel.gov, 303-384-7790
}

\begin{abstract}
Catalytic fast pyrolysis of biomass over zeolite catalysts results primarily in aromatic (e.g. benzene, toluene, xylene) and olefin products. However, furans are a higher value intermediate for their ability to be readily transformed into gasoline, diesel, and chemicals. Here we investigate possible mechanisms for the coupling of glycoaldehyde, a common product of cellulose pyrolysis, over HZSM-5 for the formation of furans. Experimental measurements of neat glycoaldehyde over a fixed bed of HZSM- 5 confirm furans (e.g. furanone) are products of this reaction at temperatures below $300^{\circ} \mathrm{C}$ with several aldol condensation products as co-products (e.g. benzoquinone). However, under typical catalytic fast pyrolysis conditions $\left(>400^{\circ} \mathrm{C}\right)$, further reactions occur that lead to the usual aromatic product slate. ONIOM calculations were utilized to identify the pathway for glycoaldehyde coupling toward furanone and hydroxyfuranone products with dehydration reactions serving as the rate determining steps with typical intrinsic reaction barriers of $40 \mathrm{kcal} \mathrm{mol}^{-1}$. The reaction mechanisms for glycoaldehyde will likely be similar to that of other small oxygenates such as acetaldehyde, lactaldehyde, and hydroxyacetone and this study provides a generalizable mechanism of oxygenate coupling and furan formation over zeolite catalysts.
\end{abstract}

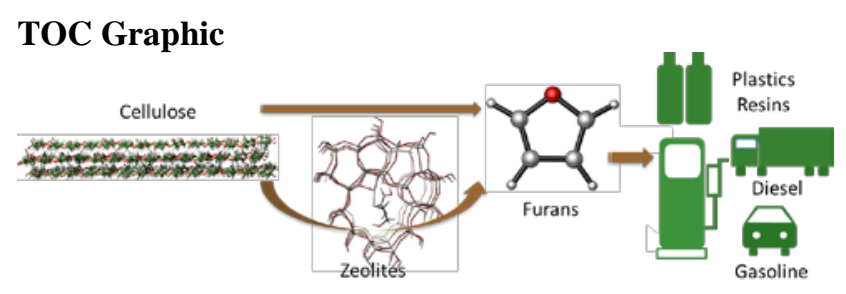

\section{Synopsis}

Identifying potential thermochemical pathways of biomass to furan, which can help biomass displace petroleum for fuels and chemicals.

\section{Introduction}

Furans are attractive and valuable target intermediates that can be formed by catalytic conversion of biomass fast pyrolysis vapors. Indeed, biochemical routes to produce furans directly from sugars have been an active area of research for quite some time. ${ }^{1-5}$ Furans can be converted into gasoline-range aromatic hydrocarbon and olefins, ${ }^{6-8}$ serve as a feedstock for diesel ${ }^{9,10}$ or gasoline fuels, ${ }^{11}$ or be used to generate higher-value chemicals. ${ }^{12,13}$ For example, Sutton et al. recently developed a novel synthesis methodology to couple furans with other biomass derived chemicals, e.g. ketones, through aldol condensation to selectively generate higher linear alkanes (bio-diesels) in good yields under mild reaction conditions. ${ }^{14}$ Unfortunately, traditional catalytic fast pyrolysis (CFP) results in only small yields of furans. Therefore, catalytic strategies to convert pyrolysis vapors to furans are currently being investigated. ${ }^{15}$

While strongly acidic zeolites have been used to completely deoxygenate bio-oils and pyrolysis vapors, other less reactive and/or partially deactivated zeolites have been shown to partially deoxygenate pyrolysis vapors to form furan and alkyl furans. ${ }^{16-20}$ French and Czernik evaluated 40 selected catalysts (including HZSM-5) for their hydrocarbon production performance on aspen wood, cellulose, and straw lignin and demonstrated formation of partially dehydrated oxygenates, such as furan, methyl furan, furfural, and methyl furfural in the products. ${ }^{17}$ Mukarakate et al. studied the conversion of pine pyrolysis vapors over fixed beds of $\beta$-zeolite and HZSM-5 and found the formation of several furan derivatives (furan, methyl furan, dimethyl furan, and trimethyl furan). ${ }^{19,20}$ Jae et al. identified 4-methyl-2,3-dihydrofuran, furfural, 5-methyl furfural, 2-furanmethanol, and 5-methyl-2(5H)-furanone in the products during CFP of glucose over 13 zeolites with a variety of pore size and shape. ${ }^{18}$ Carlson et al. identified furan, 2-methyl furan, 4-methyl-furfural, furan-2-methanol as the thermally stable oxygenated intermediates in the production of aromatics from 
fast pyrolysis of glucose, cellobiose, cellulose, and xylitol over HZSM-5 and other catalysts. ${ }^{16,21-26}$ While these studies have shown that furans are formed during CFP over zeolite catalysts, the underlying chemistry has rarely been investigated.

Mechanisms of furan formation during catalytic vapor phase conversion have not been well established, but may be surmised from pyrolysis chemistry and food chemistry. It has been widely accepted that furans can be directly formed via dehydration of cellulose and hemicellulose to produce anhydrosugar intermediates, such as levoglucosan and levoglucosenone, which in turn are converted into 5-hydroxymethyl furfural (HMF) and furfural during fast pyrolysis. ${ }^{27-29}$ Recent theoretical investigations of the pyrolysis of cellulose have calculated paths to a variety of oxygenated products, including furan, acetaldehyde, and glycoaldehyde. ${ }^{30-33}$ Investigation of their potential energy surface shows that furans are the Gibbs free energy minima for the product mixture. Therefore, we presume that furans could be produced by the coupling reactions of the oxygenated organic molecules present in the pyrolysis vapors.

Interestingly, the formation of furans by the aldol condensation of small aldehydes is also of importance to heat processing of certain foods. ${ }^{34-38}$ Mechanistic studies in that field suggest that certain amino acids can degrade and produce acetaldehyde and glycoaldehyde, which can further undergo aldol condensation to form 2-deoxyaldotetrose, cyclization to produce 2,4-dihydroxytetrahydrofuran, and finally undergo two dehydration reactions to make furan. ${ }^{36-38}$ Other furan derivatives can be synthesized in a similar manner. For instance, the coupling reaction of acetaldehyde and lactaldehyde has been proposed to be able to produce 2methyl furan. ${ }^{37}$ However, the detailed reaction mechanisms by which furan or 2-methyl furan is made from the oxygenated molecules have not been elucidated. Recently, Garrabou et al. developed a new biocatalytic strategy to use D-fructose-6-phosphate aldolase to synthesize 2,3,4-trihydroxy-tetrahydrofuran from the self-aldol reaction of glycoaldehyde. ${ }^{39}$

Since glycoaldehyde has been identified as a component of pyrolysis oils, ${ }^{40}$ we chose glycoaldehyde as the model compound to investigate the chemistry of formation of furan derivatives during catalytic upgrading of pyrolysis vapors as shown in Scheme 1.

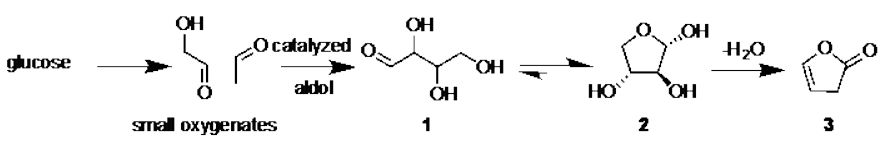

Scheme 1. Proposed pathway for conversion of carbohydrate-derived products to furans.

In this study, we aim to obtain fundamental insights into reactions of glycoaldehyde over HZSM-5, which we feel will serve as a fiducial system for the coupling and cross-coupling of other oxygenates such as acetaldehyde, lactaldehyde, and hydroxyacetone. Semi-batch reactor studies were utilized to confirm furan formation from the glycoaldehyde system and investigate the temperature dependence of the products formed. ONIOM calculations were conducted to elucidate the mechanism of this reaction at the T12 site of HZSM-5.

\section{Experimental Methods}

Materials

Glycolaldehyde dimer was purchased from Sigma-Aldrich as a mixture of stereoisomers (no purity claim). A powdered HZSM-5 catalyst (Nexceris, $\mathrm{SiO}_{2} / \mathrm{Al}_{2} \mathrm{O}_{3}=30$ ) was used in the MBMS experiments. Prior to use, the catalyst was calcined by heating at $3{ }^{\circ} \mathrm{C}$ per minute ramp to $550^{\circ} \mathrm{C}$ and held for four hours. The catalyst used in the py-GCMS (Autosampler pyrolysis-gas chromatography mass spectroscopy) were HZSM-5 spheres (Nexceris, 300-500 $\mu \mathrm{m}, \mathrm{SiO}_{2} / \mathrm{Al}_{2} \mathrm{O}_{3}=30$ ), which was pre-calcined.

\section{Gas phase chemistry over a packed bed}

A horizontal, semi-batch reactor paired with a molecular beam mass spectrometer (MBMS) was used to study the gas phase reaction products of glycolaldehyde over HZSM-5 ${ }^{41}\left(\mathrm{SiO}_{2} / \mathrm{Al}_{2} \mathrm{O}_{3}=30\right)$. A more detailed description of the system has been reported in previous studies ${ }^{15,19,20,42}$ and is only briefly mentioned here. This reactor consists of a horizontal quartz annular flow tube within a five-zone furnace used to heat the reactor to the desired temperature. Solid glycolaldehyde dimers $(\sim 30 \mathrm{mg})$ contained in quartz boats are placed in the inner tube where they are vaporized and entrained in a 0.4 slm (standard liters per minute) flow of helium. The dimer was shown to fully dissociate into two glycoaldehyde monomer units at $100^{\circ} \mathrm{C}$. The inner flow passes through a fixed catalyst bed before mixing with an outer flow of 4 slm helium, which diluted the stream to diminish secondary reactions before the vapor stream enters the MBMS. A controlled flow of $40 \mathrm{sccm}$ (standard cubic centimeters per minute) argon is included in the outer flow and used as a tracer gas. The sample boats were clean upon removal and each pulse of product vapors lasted for about 60 seconds (as observed on the MBMS), thus the weight hourly space velocity is estimated to be about $3.6 \mathrm{~h}^{-1}$.

The catalyst bed was prepared by supporting $0.5 \mathrm{~g}$ of HZSM- 5 catalyst on quartz wool. Pressure drops across the bed at room temperature $\left(20^{\circ} \mathrm{C}, 9\right.$ Torr $)$ and at reaction temperature $\left(150-300^{\circ} \mathrm{C}, 31\right.$ Torr $)$ were typical. 
Py-GCMS analysis was carried out to supplement the MBMS by confirming the identification of masses and separating compounds of the same mass. A tandem micropyrolyzer (Rx-3050TR, Frontier Laboratories, Japan) furnished with an autosampler (AS-1020E) and microjet cryo-trap (MJT-1030Ex) coupled to a gas chromatograph (7890B, Agilent Technologies, USA) and an MS (5977A, Agilent Technologies, USA) was used to identify products from conversion of glycoaldehyde over HZSM-5.

The micropyrolyzer consisted of two heating zones; one for vaporizing glycoaldehyde and the other for loading the catalyst. During the experiment deactivated stainless steel cups containing $500 \mu \mathrm{g}$ of glycolaldehyde dimer were loaded into an autosampler, which dropped them into the first furnace operated at $200^{\circ} \mathrm{C}$. This furnace vaporized the sample, the sample vapors were then entrained in a helium carrier gas, and transported through a fixed bed of HZSM-5 catalyst housed in a furnace that was set to the conversion temperature. The products emanating from the catalyst bed were then captured using a liquid nitrogen trap (held inside the GC oven) and released into the GCMS for compound separation and detection. The column (Ultra Alloy-5, Frontier Laboratories, Japan) has a 5\% diphenyl and 95\% dimethylpolysiloxane stationary phase. The oven temperature was programmed as follows: set to hold at $40^{\circ} \mathrm{C}$ for $4.5 \mathrm{~min}$ then heated to $300^{\circ} \mathrm{C}$ at the ramp rate of $20^{\circ} \mathrm{C} \mathrm{min}^{-1}$. The separated product vapors were identified using the NIST GCMS library (http://chemdata.nist.gov).

\section{Computational Methods}

Various chemical reactions catalyzed by HZSM-5 have been theoretically studied using quantum mechanical density functional theory (DFT). ${ }^{43-46}$ Since the exact location of catalytic acidic sites in HZSM-5 has not been determined experimentally, ${ }^{47,48}$ many theoretical studies, conducted using either small cluster models or large ONIOM models, are performed mainly on the T12 catalytic sites in HZSM-5, because it is the most likely site during the aluminum substitution. ${ }^{49,50}$ Following this convention, all of the calculations in the current study were conducted at the T12 site, where the silicon atom was substituted by an aluminum atom to generate a Brønsted acidic site. The combined theoretical model, ONIOM (M06-2X/6-31G(d):PM6) was applied to predict the geometries of all intermediates and transition states. Our previous studies showed that the two-layer ONIOM scheme provides a more accurate representation of charges on the framework oxygen atoms than cluster models. ${ }^{51}$

The hybrid meta generalized gradient approximation M06-2X functional ${ }^{52,53}$ was chosen since it provided better agreement with experimental results than other functionals. ${ }^{54-56}$ Maihom et al. identified M06-2X functional is well suited for adsorption energies of dimethyl ether than B3LYP and showed a good agreement with the experimental results. ${ }^{54}$ The high level DFT layer contains a $12 \mathrm{~T}$ cluster and the substrate molecule as shown in Figure 1. The framework DFT layer contains 11 silicon atoms, one substituted by an aluminum atom which is the Brønsted acid site. The silicon atoms in the DFT layer include the four coordinated around the Brønsted acid site and a 10-membered ring including the aluminum atom. The semi-empirical layer contains 295 atoms as the low level (shown in wireframe in Figure 1). To preserve the crystallographic positions of the zeolite structure during the structure optimizations, all atoms in the high-level layer were relaxed while the atoms in the low-level layer were frozen. The single point calculations were further evaluated at the level of M06-2X/6-311++G(d,p) in the high-level. All the geometry optimizations and frequency calculations were performed using the Gaussian 09 package. ${ }^{57}$ Only one imaginary frequency was observed for the transition states while none for the reactants, intermediates and products. Intrinsic reaction coordinate (IRC) calculations were performed for all transition states to confirm that they connected the corresponding energy minima. 


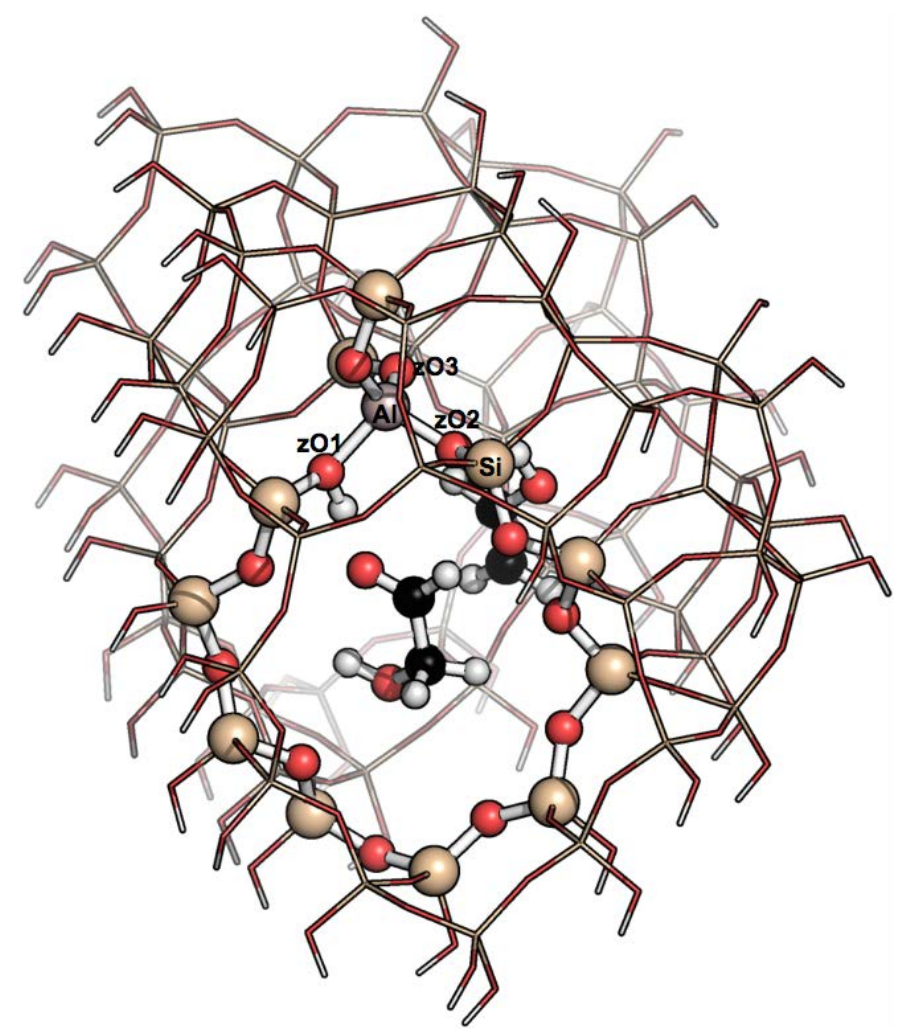

Figure 1. 12T ONIOM model with layers. The ball and stick represents high layer with the M06-2X/6-311++G(d,p)//M06-2X/6-31G(d) and wireframe represents the low layer calculated with PM6.

\section{Labeling convention}

Throughout this study we describe various geometrical parameters relevant to the chemistry occurring within the zeolite micropores. The oxygen atoms within the zeolite structure are labeled as zO1, zO2, and zO3 as shown in Figure 1. The $\mathrm{C}$, O, and $\mathrm{H}$ atoms of the furan ring are labeled according to their position on the furan ring for structure 2 as shown in Scheme 2. For example, the relevant bond distances in TS3 would be $\mathrm{R}_{\mathrm{zO} 1-\mathrm{H}}, \mathrm{R}_{\mathrm{C2}-\mathrm{O} 2}$, and $\mathrm{R}_{\mathrm{O} 2-\mathrm{H}}$ which describe the distances between the zeolite oxygen and proton, the furan carbon atom with the $\mathrm{O}$ atom that is forming the water molecule, and that same $\mathrm{O}$ atom with the zeolite proton, respectively.

\section{Results}

To investigate the idea that small carbohydrate-derived oxygenates could produce furan, we choose the self-reaction of glycoaldehyde. Glycoaldehyde is a known component of biomass pyrolysis oil with a concentration of 1-8\% and serves as a representative of small aldehydes. ${ }^{58}$

To confirm our hypothesis, the catalytic glycoaldehyde self-reaction was investigated in a semi-batch reactor setup. Glycoaldehyde dimer was used as the reactant source and was shown to thermally crack to two monomer units $<100^{\circ} \mathrm{C}$. In the first set of experiments a horizontal reactor coupled to an MBMS was used. The advantage of this setup is excellent time resolution and broad product detection. However, product specificity is limited due to convolution of several fragmentation patterns. In the second set of experiments, a py-GCMS was utilized which provides better assignment of the products due to combination of chromatography (e.g. residence times) and mass spectral assignments. In all cases the catalyst:glycoaldehyde ratio was kept to greater than 6:1 and total conversion was on the order of $1-2 \%$. 


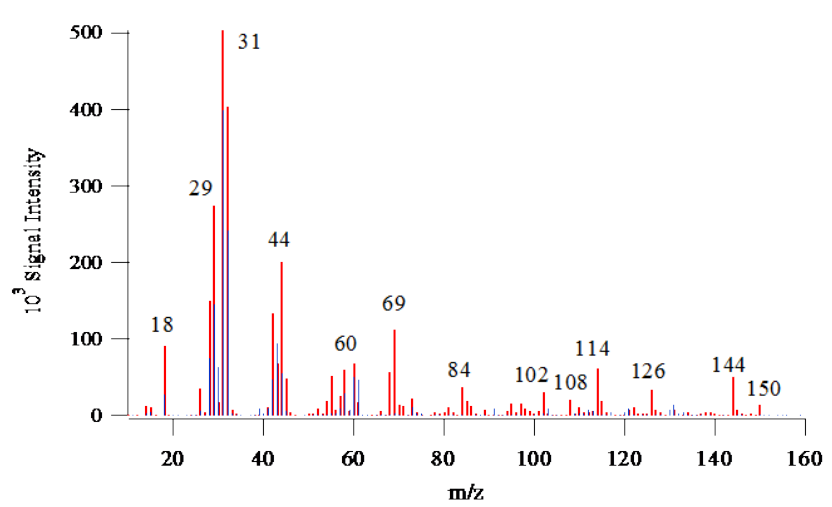

Figure 2. MBMS signal for the self-reaction of glycoaldehyde dimer over HZSM-5. Reference glycoaldehyde dimer at $250^{\circ} \mathrm{C}$ is shown in blue.

Using the MBMS setup, Figure 2 shows a variety of product peaks at $300^{\circ} \mathrm{C}$ including $\mathrm{m} / \mathrm{z} 44,60,69,84,102,108,114,126,144$ and 150. Unreacted glycoaldehyde is assigned to the peak at $\mathrm{m} / \mathrm{z} 60$ and matches well with the standard run on the same reactor without catalyst. The peaks at m/z 108, 114, 126, 144 and 150 are assigned to subsequent aldol steps (where a third aldol reaction occurred before cyclization) followed by loss of water and formaldehyde units. The peak at $\mathrm{m} / \mathrm{z} 69$ is a fragment of $\mathrm{m} / \mathrm{z} 114$. The proposed mechanism for this reaction is shown in Scheme S1 in the Supplemental Material and does not take part in furan formation chemistry of interest in this study. Similar results were also observed in the py-GCMS experiments, as described below. The remaining peaks are assigned to furanone $(\mathrm{m} / \mathrm{z} 84)$ and dihydro-hydroxy-furanone $(\mathrm{m} / \mathrm{z} 102)$. At higher temperatures $\left(>350^{\circ} \mathrm{C}\right)$, aromatic products (i.e. benzene, toluene, xylene) are observed as expected for zeolite catalysts at elevated temperatures.

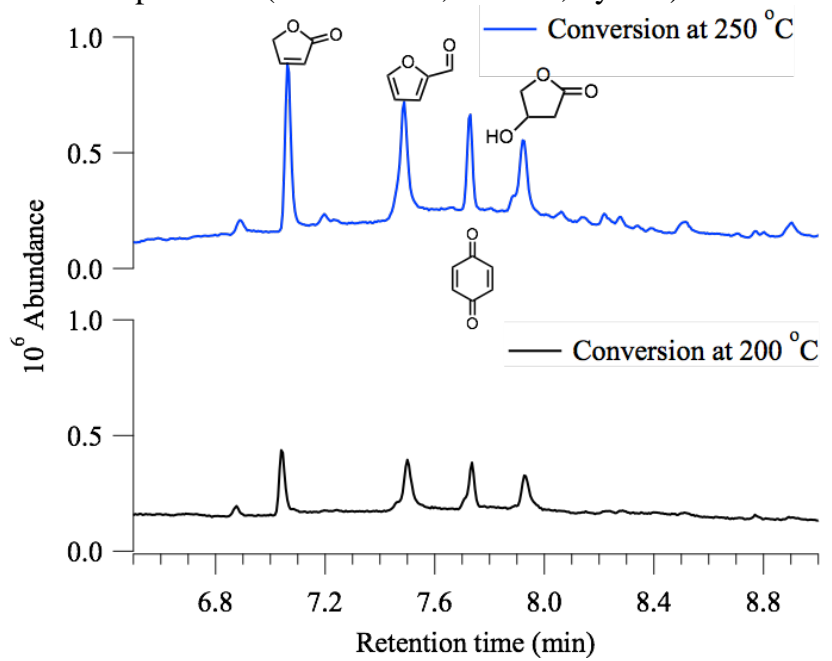

Figure 3. Chromatograms recorded during conversion of glycoaldehyde using $\mathrm{HZSM}-5$ at $200^{\circ} \mathrm{C}$ (lower panel) and $250^{\circ} \mathrm{C}$ (upper panel).

Identification of the products was aided using a py-GCMS setup. The hold-up of the sample on HZSM-5 catalyst caused the unreacted glycoaldehyde to condense back to the glycoaldehyde dimer and produce a persistent, broad background signal throughout the chromatogram. It was necessary to subtract this background signal from the chromatogram to achieve reasonable assignments of the sharper product peaks. The chromatograms are shown in Figure 3. A peak at residence time 10.7 min was also observed and assigned to 2-methyl-2-pentenoic acid (m/z 114) which, as discussed earlier, could be formed by aldol condensation of three monomer units followed by loss of two formaldehyde groups or loss of two water units and a formaldehyde unit. The four remaining peaks were assigned to 2-(5H)-furanone $(\mathrm{m} / \mathrm{z} 84)$, furfural $(\mathrm{m} / \mathrm{z} 96), p$-benzoquinone $(\mathrm{m} / \mathrm{z} 108)$, and dihydro-4-hydroxy2(3H)furanone ( $\mathrm{m} / \mathrm{z}$ 102) based on comparison to the NIST GCMS library (http://chemdata.nist.gov). 2-(5H)-furanone was further confirmed by running independent standards to match retention times as well as mass spectral signatures. It should be noted that while quality factors on the mass spectral library were typically in excess of $70 \%$, they rarely exceeded $90 \%$. 


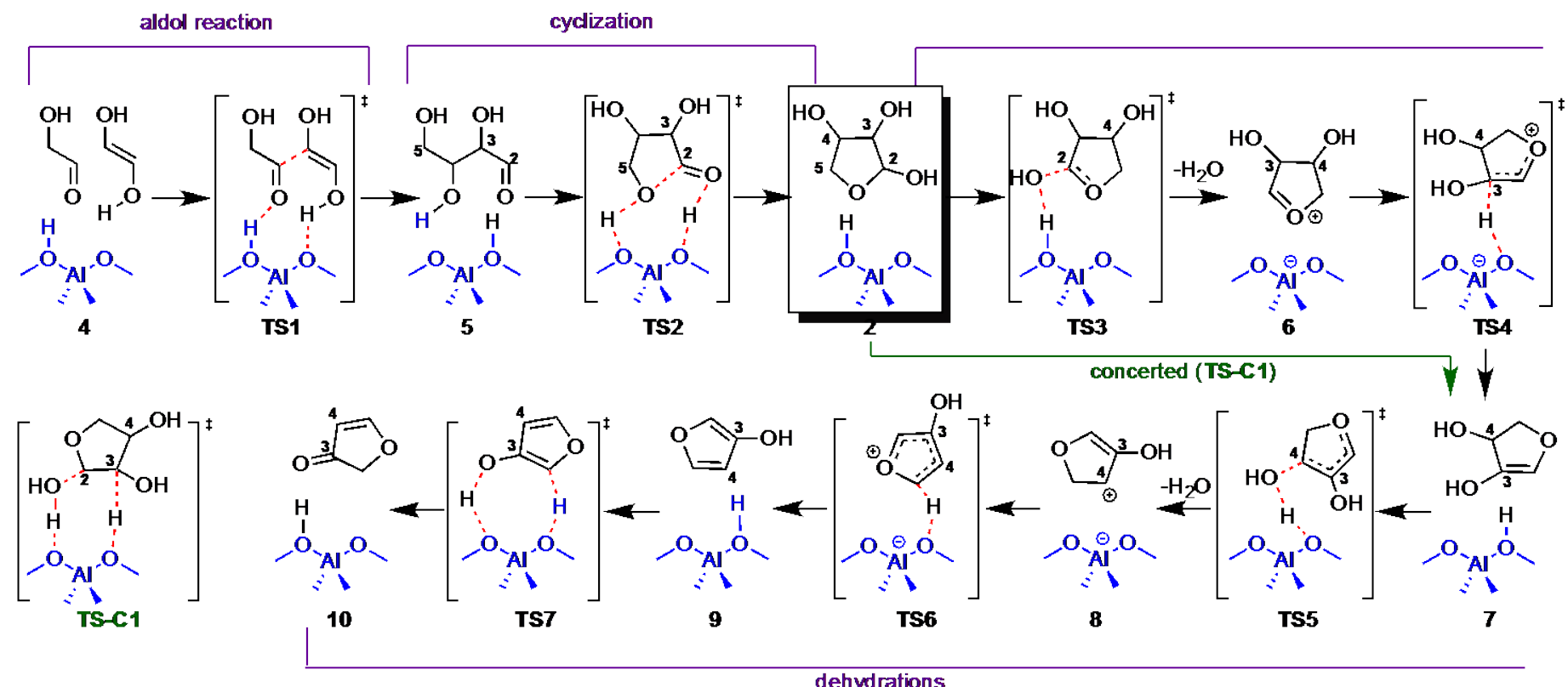

Scheme 2. Proposed pathway for the production of 3-(2H)-furanone from the coupling of glycoaldehyde by Mechanism 1. Mechanisms 2, 3 , and 4 are shown in Scheme 3 and start at structure 2. To help follow the reaction pathway, carbon atoms relevant to the current steps are labeled according to structure 2 .

Fits to other isomers, for instance 2-(3H)-furanone, tended to have quality factors less than $50 \%$. Thus, while there is high confidence in the assignments, peaks could not be unambiguously attributed to one isomer or another.

$p$-Benzoquinone is believed to be formed from aldol condensation of three monomer units followed by loss of four units of water as shown in Scheme S1 of the Supplemental Material. Only a very small peak at the parent ion for $p$-benzoquinone was observed in the gas phase detection using the horizontal reactor. Similarly furfural is a secondary or condensed phase product, formed within the cryogenic trap during heat up due to aldol condensation of three monomer units followed by loss of 3 units of water and a formaldehyde unit as shown in Scheme S1. Furfural was not observed using the horizontal reactor setup, which only enables detection of gas-phase products. 2-(5H)-furanone and dihydro-4-hydroxy-2(3H)furanone are the dominant gas-phase furan products and the focus of the theoretical investigation. Selectivity to all furan products was approximately $60 \%$, where selectivity to $2(5 \mathrm{H})$-furanone decreased with time on stream and dihydro-4-hydroxy-2(3H)-furanone increased with time on stream (Figure S1).

\section{Theoretical Investigation}

The proposed mechanisms for the formation of furan products proceed through four steps: keto/enol initiation of the glycoaldehyde, aldol condensation/ cyclization, dehydration, and a final keto-enol isomerization (Schemes 2-4).

For aldol condensation to occur, first both the keto (glycoaldehyde) and enol (1,2-ethylenediol) must be present. Under standard conditions, the keto form is grossly preferred with $\Delta \mathrm{G}_{\text {reaction(1) }}=12 \mathrm{kcal} \mathrm{mol}^{-1}$ and $16.7 \mathrm{kcal} \mathrm{mol}^{-1}$ where $K_{\text {reaction(1), 500K }}=10^{-5}$ and $10^{-8}$, as calculated at the M06-2X/6-311++G(d,p) level of theory in the absence of H-ZSM-5 and using ONIOM (M06-2X/6311++G(d,p):PM6//M06-2X/6-31G(d):PM6) with H-ZSM-5, respectively.

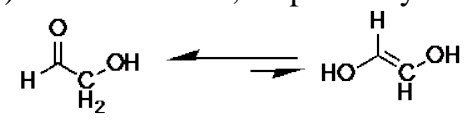

While the barrier for the keto-enol transformation in the gas phase is calculated to be large (69 $\left.\mathrm{kcal} \mathrm{mol}^{-1}\right)$, the acid site of the zeolite can catalytically reduce this to $19.1 \mathrm{kcal} \mathrm{mol}^{-1}$. Alternatively, glycoaldehyde could undergo dehydration to ketene. However, assuming a similar barrier height to ethanol $\left(45-50 \mathrm{kcal} \mathrm{mol}^{-1}\right),{ }^{51}$ direct dehydration is unlikely to be competitive. Once the enol/keto isomers are formed, carbon-carbon (C-C) coupling via aldol condensation from $\mathbf{4}$ to $\mathbf{5}$ through TS1 readily occurs via a 6 $\mathrm{kcal} \mathrm{mol}^{-1}$ barrier as shown in Figure 4. The coupling product in the case of glycoaldehyde is (D)-treose, which is well known to prefer the cyclic-furan form in aqueous solutions. Indeed, the barrier for cyclization, TS2, is only $1 \mathrm{kcal} \mathrm{mol}^{-1}$. This keto-enol coupling has also been predicted for acetaldehyde coupling to form crotonaldehyde. ${ }^{59}$ However, in that case cyclization is not possible due to the location of the oxygen functionalities. 


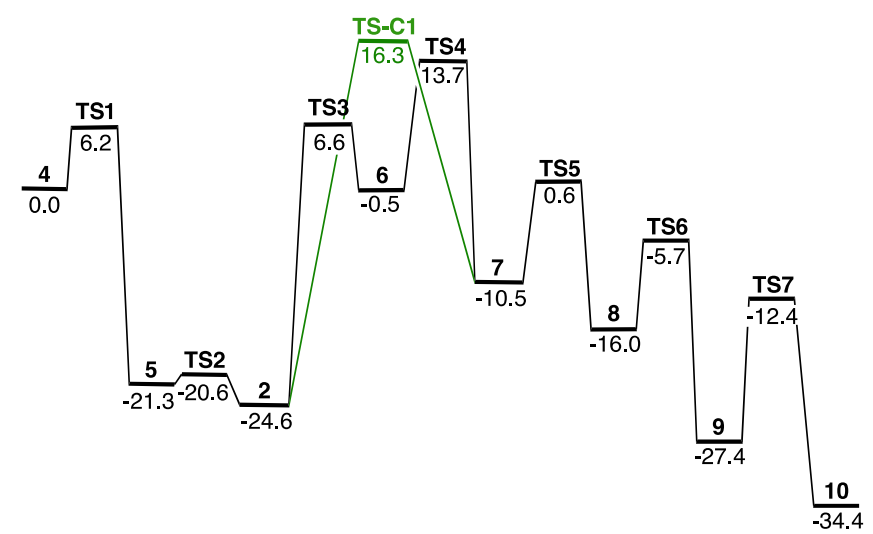

Figure 4. Free energy diagram for Mechanism 1. Gibbs free energies were calculated using M06-2X/6-311++G(d,p):PM6//M06-2X/631G(d):PM6 and are shown in $\mathrm{kcal} \mathrm{mol}^{-1}$ relative to structure 4. See Scheme 2 for structures.

After the cyclization reaction, tetrahydro-2,3,4-furantriol, 2, is formed, which is the key intermediate for the following dehydration reactions (see Scheme 2-4 for structure).

We considered only those diastereomers with a 3,4-trans relationship - the relative stereochemistry (cis/trans) is set in the aldol addition step at the start and the trans adduct was found to be formed preferentially. In catalytic self-aldol reactions of glycoaldehyde, the trans-adduct is typically formed exclusively ${ }^{60}$ or in excess. ${ }^{61,62}$ The 2-position easily undergoes epimerization via the ring-opened form, and so the stereochemistry at this position undergoes inversion rapidly. We considered both epimers of 2 ( $\mathbf{2}$ and $\mathbf{2}^{\prime}$ ) in Scheme 3. After the first dehydration step these two intermediates converge to a common set of intermediates and so the only difference in the very first step. Since the zeolite environment is achiral, enantiomeric species will be degenerate therefore the absolute stereochemistry of the intermediates is irrelevant to the reaction energetics.

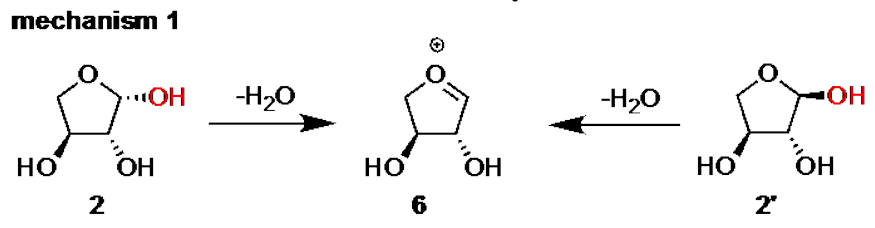

mechanism $2-4$

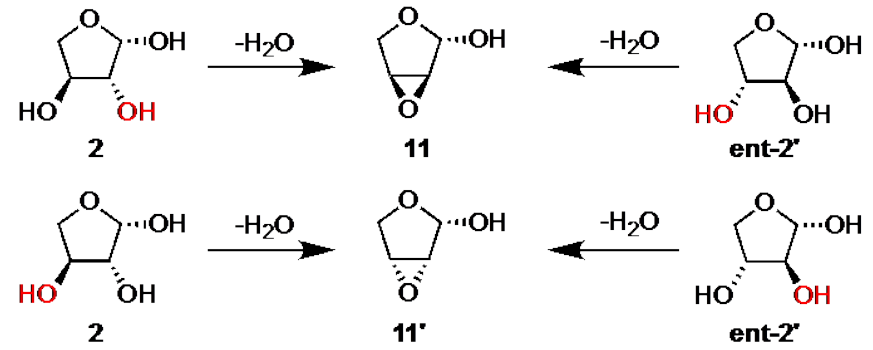

Scheme 3. All possible diastereomers of tetrahydro-2,3,4-furantriol, 2, in the first dehydration reactions for mechanism $1-4$. The $\mathrm{OH}$ group undergoing dehydration is highlighted in red.

The first dehydration step can occur at either the C2 (Mechanism 1) or C4 (Mechanisms 2-4) positions in 2. For epimer 2', it is the C3 position for Mechanisms 2-4 that is important.

Dehydration at the C2 position (Mechanism 1) should be preferred due to formation of the resonantly stable furanic oxonium ion, 6 . While dehydration at the C3 position was considered for $\mathbf{2}$ (C4 for $\mathbf{2}^{\prime}$ ), it is highly unlikely to be competitive with a barrier $>60$ $\mathrm{kcal} \mathrm{mol}^{-1}, 15-25 \mathrm{kcal} \mathrm{mol}^{-1}$ higher than dehydration at the other positions. The transition state for dehydration at the C3 position is shown in the Supplemental Material and this pathway will not be discussed further.

\section{Mechanism 1}

In Mechanism 1, dehydration occurs at the C2 position to form a furandiol intermediate, 7, by either a concerted, single-step pathway through TS-C1 or a stepwise pathway $\mathbf{2} \rightarrow \mathbf{T S} 3 \rightarrow \mathbf{6} \rightarrow \mathbf{T S} 4 \rightarrow \mathbf{7}$. The concerted pathway has a barrier of $40.9 \mathrm{kcal} \mathrm{mol}^{-1}$, while the total energy barrier for the step-wise pathway is $38.3 \mathrm{kcal} \mathrm{mol}^{-1}$. These energies were not changed significantly due to the 
epimer of 2 used in the calculations. The difference in energy between the concerted and step-wise barriers is small enough to be within the uncertainty for the method. Relevant bond lengths for the concerted and stepwise transition states are shown in Figure 5.

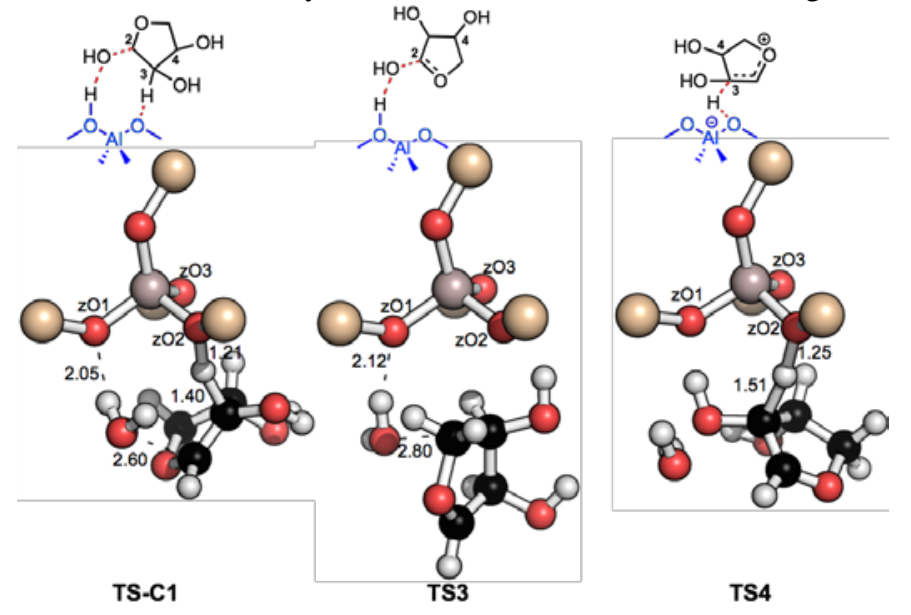

Figure 5. Geometry comparisons of concerted and stepwise transition states for the first dehydration step in Mechanism 1. Carbon atoms in black and oxygen atoms in red. Bond lengths are in Angstroms.

In the concerted transition state (TS-C1), the bond length between the zeolite oxygen and the proton is $\mathrm{R}_{\mathrm{zO}-\mathrm{H}}=2.05 \AA$, the oxygen on 2 and the proton is $\mathrm{R}_{\mathrm{O} 2-\mathrm{H}}=0.97 \AA$, and the $\mathrm{C}-\mathrm{O}$ bond length in tetrahydro-2,3,4-furantriol is $\mathrm{R}_{\mathrm{C} 2-\mathrm{O} 2}=2.60 \AA$. These bond lengths show that an independent water molecule has formed at the transition state. The bond length between a second framework oxygen, zO2, and the proton from C3 of 2 is $\mathrm{R}_{\mathrm{zO} 2-\mathrm{H} 3}=1.21 \AA$ and the $\mathrm{C} 3-$ proton distance is $\mathrm{R}_{\mathrm{C} 3-\mathrm{H} 3}=1.40 \AA$, showing the proton has partially transferred from the furan ring to the zeolite framework to regenerate the zeolite acid site. The concerted mechanism for the first dehydration reaction indicates the transition state is "late" or close to the product structure, similar to our previous study on ethanol dehydration. ${ }^{51}$

The transition states (TS3 and TS4) for the stepwise mechanism also exhibit characteristics of late transition states as shown in Figure 5. In TS3, the bond length from framework oxygen to the proton is $\mathrm{R}_{\mathrm{zO} 1-\mathrm{H}}=2.12 \AA$, while the distance between $\mathrm{O} 2$ of tetrahydro-2,3,4-furantriol (2) and the proton is $\mathrm{R}_{\mathrm{O} 2-\mathrm{H}}=0.98 \AA$ and the C2-O2 bond is essentially broken in TS3 at $\mathrm{R}_{\mathrm{C} 2-\mathrm{O} 2}=2.80 \AA$. The bond lengths indicate the conformation of TS3 is close to the product structure with distinct water and furanol species. The product of TS3 is structure 6, which is a furanic oxonium species. These cyclic cations are generally considered stable within zeolite structures. ${ }^{63,64}$ The second transition state, TS4, of the stepwise mechanism involves a hydrogen transfer back to the zeolite framework and release of the dehydrated product, 7. The bond lengths between the framework oxygen and the proton of furandiol cation substrate, $\mathbf{6}$, is $\mathrm{R}_{\mathrm{zO} 2-\mathrm{H} 3}=1.25 \AA$ and $\mathrm{C}-\mathrm{H}$ bond length of $\mathbf{6}$ is $\mathrm{R}_{\mathrm{C} 3-\mathrm{H} 3}=1.51 \AA$, which is close to the bond lengths in the product structure, 7.

Two routes are possible once 2,3-dihydrofuran-3,4-diol, 7, is formed. First, a keto/enol isomerization can occur forming dihydrofuran-3(2H)-one,4-ol, 7-keto. While the keto-isomer is the more stable of the two isomers, the barrier to isomerization is $28.7 \mathrm{kcal} \mathrm{mol}^{-1}$, which is relatively high compared to direct dehydration via TS5 $\left(11 \mathrm{kcal} \mathrm{mol}^{-1}\right)$, as shown in Figure S2 in the Supplemental Material. The second dehydration reaction occurs at the C4 position to form a carbocation intermediate, 8, releasing a second water molecule via TS5. The catalyst is regenerated via TS6 where a proton transfer at the C5 position to form 3-furanol, 9. 3-Furanol can undergo a final keto/enol isomerization to the more stable 3-(2H)-furanone structure, 10, as shown in Scheme 2, via TS7. The barrier for this final isomerization is $15 \mathrm{kcal} \mathrm{mol}^{-1}$.

\section{Mechanisms 2-4}




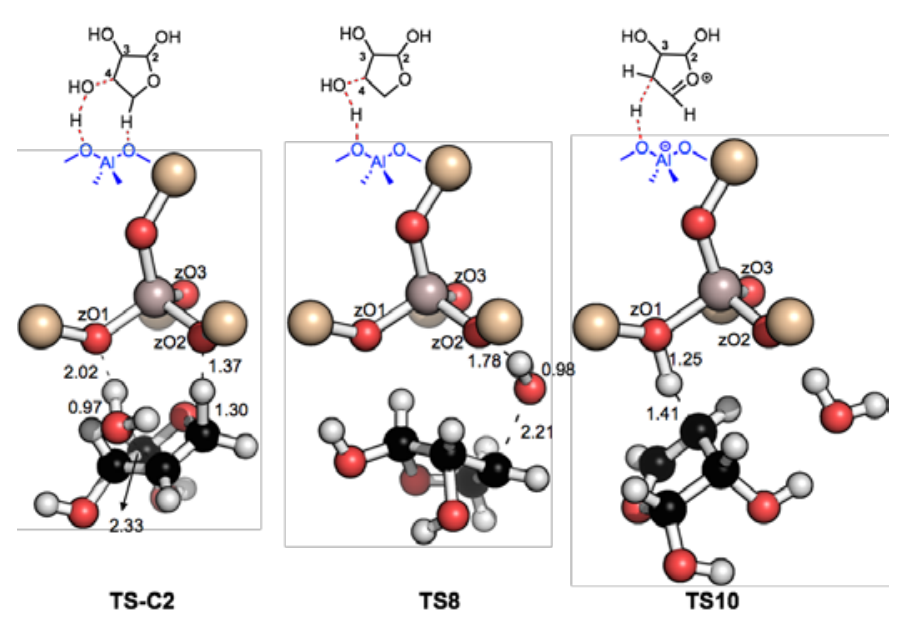

Figure 6. Geometry comparisons of concerted and stepwise transition states for the first dehydration step in Mechanism 2. Bond lengths are in $\AA$.

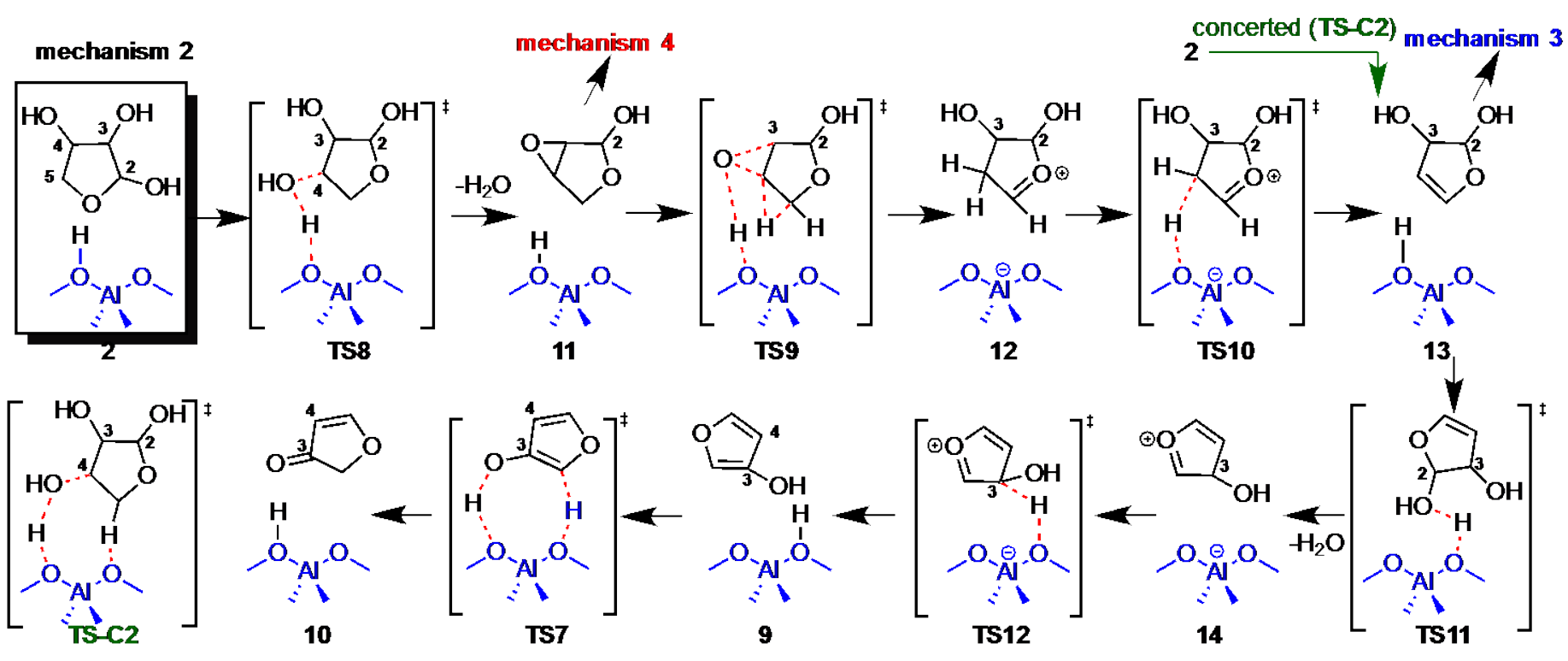

mechanism 3
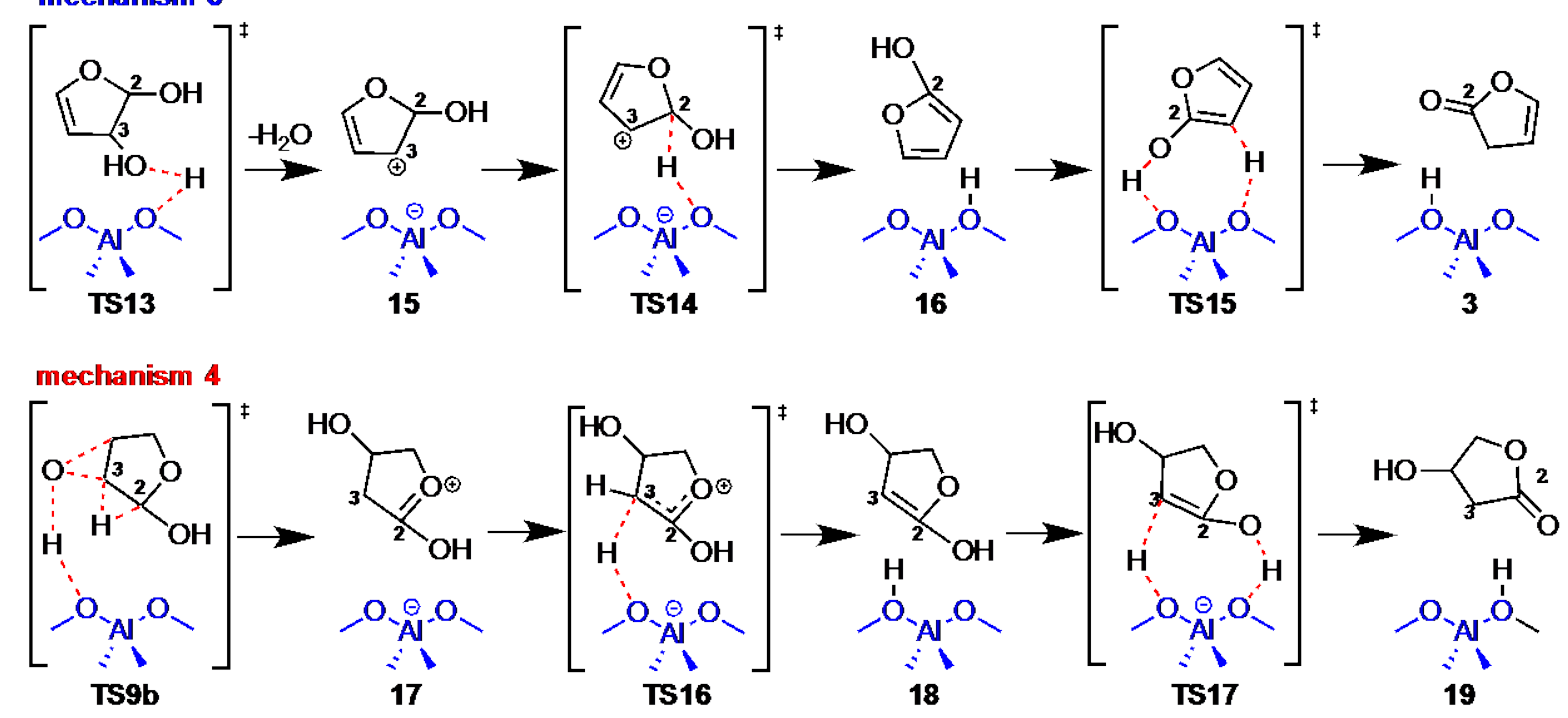
Scheme 4. Proposed pathway for Mechanisms 2-4. Mechanism 2 deviates from Mechanism 1 at structure 2, Mechanism 3 deviates from Mechanism 2 at structure 13. Mechanism 4 begins at structure 11. To help follow the reaction pathway, carbon atoms relevant to the current steps are labeled according to structure 2.

Mechanisms 2-4 (Scheme 4) also start from tetrahydro-2,3,4-furantriol, 2, and initiate through dehydration at position C4 (or C3 if epimer $\mathbf{2}^{\prime}$ is the starting point), but deviate at different points after that. Transition states for the first dehydration step in Mechanism 2 and 3 are shown in Figure 6.

Mechanisms 2 and 3 proceed via dehydration through TS9 (or TS-C2) to structure 13. The two mechanisms deviate at that point, where Mechanism 2 undergoes further dehydration at the C2 position, while Mechanism 3 dehydrates at the C3 position. A final keto/enol isomerization results in 3-(2H)-furanone, 3, and 2-(3H)-furanone, 10, respectively. Mechanism 4 splits at structure 11 and proceeds through TS9b to eventually form dihydro-4-hydroxy-2(3H)furanone, structure 19. The potential energy surface is illustrated in Figure 7, where the highest barrier is the first dehydration step, TS8.

The first dehydration at the C4 position of structure $\mathbf{2}$ was investigated by both the stepwise and concerted pathways similar to what was discussed for Mechanism 1 above. The stepwise pathway is preferred by approximately $2.6 \mathrm{kcal} \mathrm{mol}^{-1}$. Similar to Mechanism 1, the difference between the concerted and stepwise barrier heights is within the uncertainty of the computational method and it would be unwise to ascribe significance to such a small difference. However, this concerted pathway bypasses the ability to form $\mathbf{1 1}$ necessary for Mechanism 4. If dehydration is considered at the C3 position of epimer 2', the stepwise barrier reduces by $6.3 \mathrm{kcal} \mathrm{mol}^{-1}$ and will therefore preferentially proceed through the stepwise mechanism to form $\mathbf{1 1}$.

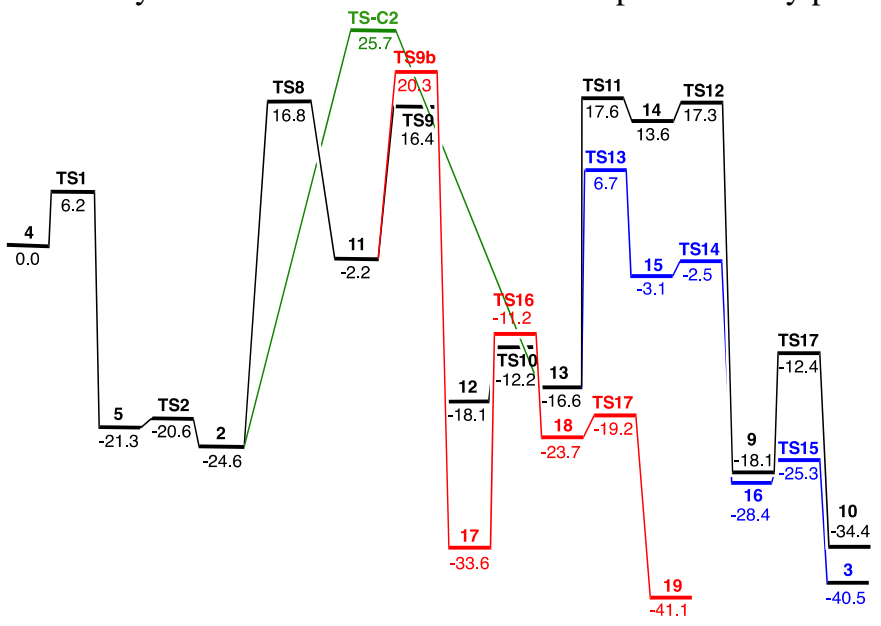

Figure 7. Free energy diagram for Mechanisms 2 (black), 3 (blue), and 4 (red). Gibbs free energies were calculated using M06-2X/6311++G(d,p):PM6//M06-2X/6-31G(d):PM6 and are shown in kcal mol ${ }^{-1}$ relative to structure 4. See Scheme 4 for structures.

For the concerted pathway, we again see that the transition state is 'late' with a fully formed water molecule present. The various bond lengths are also somewhat similar between TS-C1 and TS-C2. For instance, the $\mathrm{R}_{\mathrm{zO} 1-\mathrm{H}}$ bond is 2.05 and $2.02 \AA$, for the two transition states respectively. While the $\mathrm{R}_{\mathrm{zO} 2-\mathrm{H} 3}$ in TS-C1 is $1.21 \AA$, the analogous bond length in TS-C2, $\mathrm{R}_{\mathrm{zO}-\mathrm{H} 5}$ is $1.37 \AA$.

Unlike Mechanism 1, the current stepwise pathway, $\mathbf{2}$ (or $\left.\mathbf{2}^{\prime}\right) \rightarrow \mathbf{T S 8} \rightarrow \rightarrow \mathbf{1 3}$, involves a proton transfer to the zeolite to form $\mathbf{1 1}$. Due to the symmetry of the oxirane intermediate, 11, two products can be expected: the pathway following TS9 leads to a diol species, 13, where the $\mathrm{OH}$ groups are ortho to each other. Alternatively, TS9b, leads to the oxygen groups being further apart, 3.77 $\AA$, and is the same product as dehydration at the C3 position of structure 2. Production of $\mathbf{1 3}$ is slightly favored with a barrier height (TS9) that is approximately $4 \mathrm{kcal} \mathrm{mol}^{-1}$ lower than TS9b. The result of following TS9b is discussed later as Mechanism 4.

Once intermediate $\mathbf{1 3}$ is formed either of the remaining $\mathrm{OH}$ groups can undergo dehydration and this is where Mechanisms 2 and 3 deviate. Mechanism 2 follows dehydration at the C2 position, whereas Mechanism 3 undergoes dehydration at the C3 position. The barrier for dehydration at the C3 position via TS13 (Mechanism 3) is lower by $10.9 \mathrm{kcal} \mathrm{mol}^{-1}$ and forms 2-furanol. The final product of mechanisms 2 and 3 can undergo a final keto/enol isomerization to form 3-(2H)-furanone, 10, and 2-(3H)-furanone, 3, respectively. Furthermore, 2-(3H)-furanone, structure 3, can isomerize quickly over acidic catalysts to the more stable 2-(5H)furanone as shown in Scheme 5. 2-(5H)-furanone is one of major products in our py-GCMS experiments shown in Figure 3.

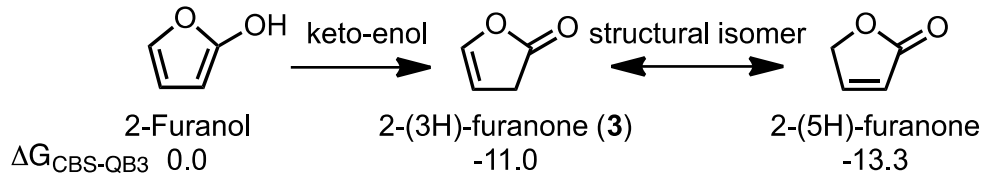

Scheme 5. Enol-keto isomerization and structural isomer from 2- furanol to 2-furanone with relative free energies $\left(\mathrm{kcal}^{\mathrm{mol}}{ }^{-1}\right)$. 
Mechanism 4 is shown in Scheme 4 and follows the pathway through TS9b leading to structure 18, which can undergo a keto-enol isomerization to the stable dihydro-4-hydroxy-2(3H)furanone, 19. We also confirmed product 19 from py-GCMS experiments (Figure 3) that shows good agreement between theory and experiment. Further dehydration of this structure is hindered due to large barriers $\left(49.5 \mathrm{kcal} \mathrm{mol}^{-1}\right)$ which were omitted from Figure 7 for visual clarity. The final dehydration product could be either 2(3H)- or 2-(5H)-furanone depending on which $\mathrm{H}$ is involved in the dehydration step. As shown in Scheme 5, either product will quickly isomerize to the more stable 2-(5H)-furanone over acidic zeolites.

When comparing Mechanisms 1-4, it is clear that the highest barriers are the first dehydration event starting at structure 2. Based on the level of theory used, dehydration at C2 (Mechanism 1) should be preferred with an overall intrinsic barrier of $38.3 \mathrm{kcal} \mathrm{mol}^{-1}$, $3.1 \mathrm{kcal} \mathrm{mol}^{-1}$ lower in energy than dehydration at position C4 (or C3 for 2') (Mechanisms 2-4).

The detection of dihydro-4-hydroxy-2(3H)furanone, 19, provides indirect evidence that the stepwise pathway is preferred over the concerted dehydration as we could find no plausible pathway to $\mathbf{1 9}$ without the stepwise intermediate, structure 11. This is in good agreement with the barriers shown in Figure 7, and suggests that $\mathbf{2}^{\prime}$ is a key intermediate on the potential energy surface. Detection of 2-(5H)-furanone supports both Mechanisms 3 and 4, as it is the final dehydration product for both. This is in agreement with the calculations that Mechanism 2 is less likely to occur over Mechanism 3. However, it was surprising that 3-(2H)-furanone was not observed experimentally as these calculations predict that Mechanism 1 should be competitive. This could be suggestive that the product distribution is controlled by thermodynamics instead of kinetics.

While this work shows the coupling of glycoaldehyde to form furanones and hydroxyfuranones, it should be noted that in CFP of whole biomass (e.g. pine) coupling reactions would occur between glycoaldehyde and a variety of other small oxygenated species both produced from pyrolysis and from catalytic cracking of the carbohydrate derived products. For instance, assuming the chemistry outlined in this study, glycoaldehyde and acetaldehyde would likely produce furan. During CFP methylation reactions are rampant and therefore methyl furans would also be expected. Ultimately, this work provides insight into one aspect of the broader zeolite chemistry slate and serves a basis for future catalyst design necessary to make furan formation a favored pathway even at higher temperatures.

\section{Acknowledgements}

This work was conducted as part of the Computational Pyrolysis Consortium supported by the U.S. Department of Energy's Bioenergy Technologies Office (DOE-BETO) Contract No. DE-AC36-08G028308 with the National Renewable Energy Laboratory. Computer time was provided by the Texas Advanced Computing Center under the National Science Foundation Extreme Science and Engineering Discovery Environment Grant MCB-090159 and by the National Renewable Energy Laboratory Computational Sciences Center. RSP acknowledges support from the SCG Innovation Fund (Catalysis in Confined Spaces). We would like to thank Ashley Berninghaus and Kristiina Iisa for some final experiments to address reviewer comments.

\section{References}

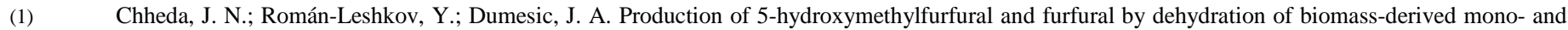
poly-saccharides. Green Chem. 2007, 9, 342-350.

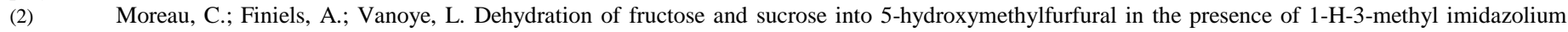
chloride acting both as solvent and catalyst. J. Mol. Catal. A: Chem. 2006, 253, 165-169.

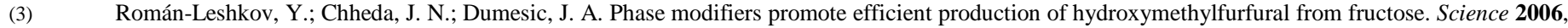
312, 1933-1937.

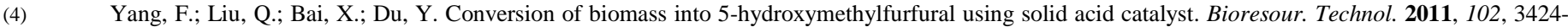
3429.

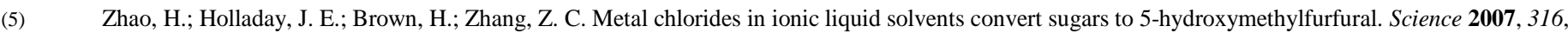
1597-1600.

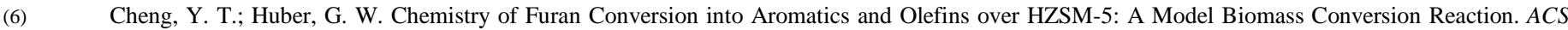
Catal. 2011, 1, 611-628.

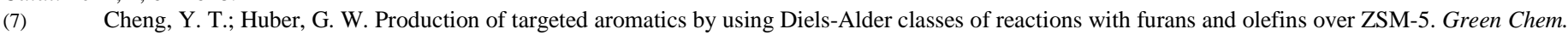
2012, 14, 3114-3125

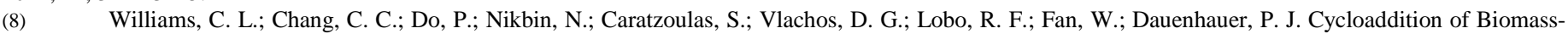
Derived Furans for Catalytic Production of Renewable p-Xylene. ACS Catal. 2012, 2, 935-939.

(9) Alonso, D. M.; Bond, J. Q.; Dumesic, J. A. Catalytic conversion of biomass to biofuels. Green Chem. 2010, 12 , $1493-1513$.

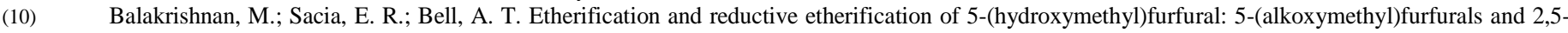
bis(alkoxymethyl)furans as potential bio-diesel candidates. Green Chem. 2012, 14, 1626-1634.

(11) Eldeeb, M. A.; Akih-Kumgeh, B. Reactivity Trends in Furan and Alkyl Furan Combustion. Energy Fuels 2014, $28,6618-6626$.

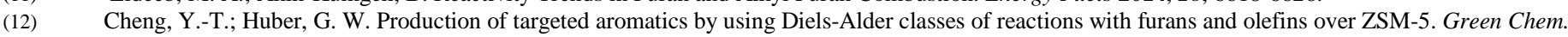
2012, 14, 3114-3125.

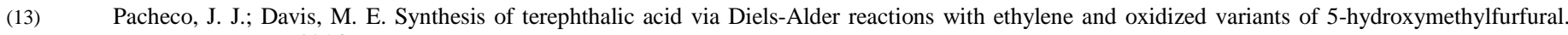
Proc. Natl. Acad. Sci. U. S. A. 2014, 111, 8363-8367.

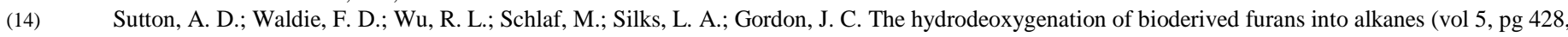
2013). Nat. Chem. 2013, 5, 544-544. 
(15) Budhi, S.; Mukarakate, C.; Iisa, K.; Pylypenko, S.; Ciesielski, P. N.; Yung, M. M.; Donohoe, B. S.; Katahira, R.; Nimlos, M. R.; Trewyn, B. G. Molybdenum incorporated mesoporous silica catalyst for production of biofuels and value-added chemicals via catalytic fast pyrolysis. Green Chem. 2015, 17, 3035-3046.

(16) Carlson, T. R.; Tompsett, G. A.; Conner, W. C.; Huber, G. W. Aromatic Production from Catalytic Fast Pyrolysis of Biomass-Derived Feedstocks. Top. Catal. 2009, 52, 241-252.

(17) French, R.; Czernik, S. Catalytic pyrolysis of biomass for biofuels production. Fuel Process. Technol. 2010, 91, 25-32.

(18) Jae, J.; Tompsett, G. A.; Foster, A. J.; Hammond, K. D.; Auerbach, S. M.; Lobo, R. F.; Huber, G. W. Investigation into the shape selectivity of zeolite catalysts for biomass conversion. J. Catal. 2011, 279, 257-268.

(19) Mukarakate, C.; Watson, M. J.; ten Dam, J.; Baucherel, X.; Budhi, S.; Yung, M. M.; Ben, H.; Iisa, K.; Baldwin, R. M.; Nimlos, M. R. Upgrading biomass pyrolysis vapors over $\beta$-zeolites: role of silica-to-alumina ratio. Green Chem. 2014, DOI: 10.1039/C4GC01425A

(20) Mukarakate, C.; Zhang, X. D.; Stanton, A. R.; Robichaud, D. J.; Ciesielski, P. N.; Malhotra, K.; Donohoe, B. S.; Gjersing, E.; Evans, R. J.; Heroux, D. S.; Richards, R.; Iisa, K.; Nimlos, M. R. Real-time monitoring of the deactivation of HZSM-5 during upgrading of pine pyrolysis vapors. Green Chem. 2014, 16, 1444-1461.

(21) Carlson, T. R.; Vispute, T. R.; Huber, G. W. Green gasoline by catalytic fast pyrolysis of solid biomass derived compounds. Chemsuschem 2008, 1, 397-

400 .

(22) Adam, J.; Blazsó, M.; Mészáros, E.; Stöcker, M.; Nilsen, M. H.; Bouzga, A.; Hustad, J. E.; Grønli, M.; Øye, G. Pyrolysis of biomass in the presence of Al-MCM-41 type catalysts. Fuel 2005, 84, 1494-1502.

(23) Lu, Q.; Dong, C.-q.; Zhang, X.-m.; Tian, H.-y.; Yang, Y.-p.; Zhu, X.-f. Selective fast pyrolysis of biomass impregnated with ZnCl2 to produce furfural: Analytical Py-GC/MS study. J. Anal. Appl. Pyrolysis 2011, 90, 204-212.

(24) Lu, Q.; Zhang, Z.-F.; Dong, C.-Q.; Zhu, X.-F. Catalytic Upgrading of Biomass Fast Pyrolysis Vapors with Nano Metal Oxides: An Analytical PyGC/MS Study. Energies 2010, 3, 1805.

(25) Lu, Q.; Zhang, Y.; Tang, Z.; Li, W.-z.; Zhu, X.-f. Catalytic upgrading of biomass fast pyrolysis vapors with titania and zirconia/titania based catalysts. Fuel 2010, 89, 2096-2103.

(26) Lu, Q.; Wang, Z.; Dong, C.-q.; Zhang, Z.-f.; Zhang, Y.; Yang, Y.-p.; Zhu, X.-f. Selective fast pyrolysis of biomass impregnated with ZnCl2: Furfural production together with acetic acid and activated carbon as by-products. J. Anal. Appl. Pyrolysis 2011, 91, 273-279.

(27) Kawamoto, H.; Saito, S.; Hatanaka, W.; Saka, S. Catalytic pyrolysis of cellulose in sulfolane with some acidic catalysts. J. Wood Sci. 2007, 53, 127-133.

(28) Vinu, R.; Broadbelt, L. J. A mechanistic model of fast pyrolysis of glucose-based carbohydrates to predict bio-oil composition. Energy Environ. Sci. 2012, 5, 9808-9826.

(29) Mihalcik, D. J.; Mullen, C. A.; Boateng, A. A. Screening acidic zeolites for catalytic fast pyrolysis of biomass and its components. J. Anal. Appl. Pyrolysis 2011, 92, 224-232.

(30) Mayes, H. B.; Nolte, M. W.; Beckham, G. T.; Shanks, B. H.; Broadbelt, L. J. The Alpha-Bet(a) of Glucose Pyrolysis: Computational and Experimental Investigations of 5-Hydroxymethylfurfural and Levoglucosan Formation Reveal Implications for Cellulose Pyrolysis. ACS Sustainable Chem. Eng. 2014, 2, 14611473.

(31) Zhou, X.; Nolte, M. W.; Shanks, B. H.; Broadbelt, L. J. Experimental and Mechanistic Modeling of Fast Pyrolysis of Neat Glucose-Based Carbohydrates. 2. Validation and Evaluation of the Mechanistic Model. Ind. Eng. Chem. Res. 2014, 53, 13290-13301.

(32) Burnham, A. K.; Zhou, X.; Broadbelt, L. J. Critical Review of the Global Chemical Kinetics of Cellulose Thermal Decomposition. Energy Fuels 2015, 29, 2906-2918.

(33) Zhou, X.; Nolte, M. W.; Mayes, H. B.; Shanks, B. H.; Broadbelt, L. J. Experimental and Mechanistic Modeling of Fast Pyrolysis of Neat Glucose-Based Carbohydrates. 1. Experiments and Development of a Detailed Mechanistic Model. Ind. Eng. Chem. Res. 2014, 53, 13274-13289.

(34) Crews, C.; Castle, L. A review of the occurrence, formation and analysis of furan in heat-processed foods. Trends Food Sci. Technol. 2007, 18, 365-372.

(35) Yaylayan, V. A.; Locas, C. P. Vinylogous Amadori rearrangement: Implications in food and biological systems. Mol. Nutr. Food Res. 2007, 51, 437-444.

(36) Locas, C. P.; Yaylayan, V. A. Origin and mechanistic pathways of formation of the parent furan - A food toxicant. J. Agric. Food. Chem. 2004, 52, 6830-6836.

(37) Mark, J.; Pollien, P.; Lindinger, C.; Blank, I.; Mark, T. Quantitation of furan and methylfuran formed in different precursor systems by proton transfer reaction mass spectrometry. J. Agric. Food. Chem. 2006, 54, 2786-2793.

(38) Limacher, A.; Kerler, J.; Davidek, T.; Schmalzried, F.; Blank, I. Formation of furan and methylfuran by Maillard-type reactions in model systems and food. J. Agric. Food. Chem. 2008, 56, 3639-3647.

(39) Garrabou, X.; Castillo, J. A.; Guerard-Helaine, C.; Parella, T.; Joglar, J.; Lemaire, M.; Clapes, P. Asymmetric self- and cross-aldol reactions of glycolaldehyde catalyzed by D-fructose-6-phosphate aldolase. Angew Chem Int Ed Engl 2009, 48, 5521-5525.

(40) Talmadge, M. S.; Baldwin, R. M.; Biddy, M. J.; McCormick, R. L.; Beckham, G. T.; Ferguson, G. A.; Czernik, S.; Magrini-Bair, K. A.; Foust, T. D.; Metelski, P. D.; Hetrick, C.; Nimlos, M. R. A perspective on oxygenated species in the refinery integration of pyrolysis oil. Green Chem. 2014, 16, 407-453.

(41) Kokotailo, G. T.; Lawton, S. L.; Olson, D. H.; Olson, D. H.; Meier, W. M. Structure of Synthetic Zeolite Zsm-5. Nature 1978, $272,437-438$.

(42) Evans, R. J.; Milne, T. A. Molecular characterization of the pyrolysis of biomass. Energy Fuels 1987, 1, 123-137.

(43) Bhan, A.; Joshi, Y. V.; Delgass, W. N.; Thomson, K. T. DFT investigation of alkoxide formation from olefins in H-ZSM-5. J. Phys. Chem. B 2003, 107, 10476-10487.

(44) Van Speybroeck, V.; Van der Mynsbrugge, J.; Vandichel, M.; Hemelsoet, K.; Lesthaeghe, D.; Ghysels, A.; Marin, G. B.; Waroquier, M. First Principle Kinetic Studies of Zeolite-Catalyzed Methylation Reactions. J. Am. Chem. Soc. 2011, 133, 888-899.

(45) Hansen, N.; Kerber, T.; Sauer, J.; Bell, A. T.; Keil, F. J. Quantum Chemical Modeling of Benzene Ethylation over H-ZSM-5 Approaching Chemical Accuracy: A Hybrid MP2:DFT Study. J. Am. Chem. Soc. 2010, 132, 11525-11538.

(46) Cheng, L.; Curtiss, L. A.; Assary, R. S.; Greeley, J.; Kerber, T.; Sauer, J. Adsorption and Diffusion of Fructose in Zeolite HZSM-5: Selection of Models and Methods for Computational Studies. J. Phys. Chem. C 2011, 115, 21785-21790.

(47) Sklenak, S.; Dedecek, J.; Li, C.; Wichterlova, B.; Gabova, V.; Sierka, M.; Sauer, J. Aluminium siting in the ZSM-5 framework by combination of high resolution Al-27 NMR and DFT/MM calculations. PCCP 2009, 11, 1237-1247.

(48) Sklenak, S.; Dedecek, J.; Li, C. B.; Wichterlova, B.; Gabova, V.; Sierka, M.; Sauer, J. Aluminum siting in silicon-rich zeolite frameworks: A combined high-resolution Al-27 NMR spectroscopy and quantum mechanics/molecular mechanics study of ZSM-5. Angew. Chem., Int. Ed. 2007, 46, 7286-7289.

(49) Gonzales, N. O.; Bell, A. T.; Chakraborty, A. K. Density Functional Theory Calculations of the Effects of Local Composition and Defect Structure on the Proton Affinity of H-ZSM-5. J. Phys. Chem. B 1997, 101, 10058-10064.

(50) Lonsinger, S.; Chakraborty, A.; Theodorou, D.; Bell, A. The effects of local structural relaxation on aluminum siting within H-ZSM-5. Catal. Lett. 1991, $11,209-217$ 
(51) Kim, S.; Robichaud, D. J.; Beckham, G. T.; Paton, R. S.; Nimlos, M. R. Ethanol Dehydration in HZSM-5 Studied by Density Functional Theory: Evidence for a Concerted Process. J. Phys. Chem. A 2015, 119, 3604-3614.

(52) Zhao, Y.; Truhlar, D. G. Density Functionals with Broad Applicability in Chemistry. Acc. Chem. Res. 2008, 41, 157-167.

(53) Zhao, Y.; Truhlar, D. G. Benchmark Data for Interactions in Zeolite Model Complexes and Their Use for Assessment and Validation of Electronic Structure Methods. J. Phys. Chem. C 2008, 112, 6860-6868.

(54) Maihom, T.; Boekfa, B.; Sirijaraensre, J.; Nanok, T.; Probst, M.; Limtrakul, J. Reaction Mechanisms of the Methylation of Ethene with Methanol and Dimethyl Ether over H-ZSM-5: An ONIOM Study. J. Phys. Chem. C 2009, 113, 6654-6662.

(55) Kumsapaya, C.; Bobuatong, K.; Khongpracha, P.; Tantirungrotechai, Y.; Limtrakul, J. Mechanistic Investigation on 1,5- to 2,6-Dimethylnaphthalene Isomerization Catalyzed by Acidic $\beta$ Zeolite: ONIOM Study with an M06-L Functional. J. Phys. Chem. C 2009, 113, 16128-16137.

(56) Kongpatpanich, K.; Nanok, T.; Boekfa, B.; Probst, M.; Limtrakul, J. Structures and reaction mechanisms of glycerol dehydration over H-ZSM-5 zeolite: a density functional theory study. PCCP 2011, 13, 6462-6470.

(57) Frisch, M. J.; Trucks, G. W.; Schlegel, H. B.; Scuseria, G. E.; Robb, M. A.; Cheeseman, J. R.; Scalmani, G.; Barone, V.; Mennucci, B.; Petersson, G. A. et al. Gaussian 09; Gaussian, Inc. 2009.

(58) Branca, C.; Giudicianni, P.; Di Blasi, C. GC/MS Characterization of Liquids Generated from Low-Temperature Pyrolysis of Wood. Ind. Eng. Chem. Res. 2003, 42, 3190-3202.

(59) Liu, C.; Evans, T. J.; Cheng, L.; Nimlos, M. R.; Mukarakate, C.; Robichaud, D. J.; Assary, R. S.; Curtiss, L. A. Catalytic upgrading of biomass-derived compounds via C-C coupling reactions: Computational and experimental studies of furan and acetaldehyde reactions in HZSM-5. J. Phys. Chem. C 2015, 119, 24025-24035.

(60) Garrabou, X.; Castillo, J. A.; Guérard-Hélaine, C.; Parella, T.; Joglar, J.; Lemaire, M.; Clapés, P. Asymmetric Self- and Cross-Aldol Reactions of Glycolaldehyde Catalyzed by D-Fructose-6-phosphate Aldolase. Angew. Chem. Int. Ed. 2009, 48, 5521-5525.

(61) Pizzarello, S.; Weber, A. L. Prebiotic Amino Acids as Asymmetric Catalysts. Science 2004, 303, 1151-1151.

(62) Assary, R. S.; Curtiss, L. A. Comparison of Sugar Molecule Decomposition through Glucose and Fructose: A High-Level Quantum Chemical Study. Energy Fuels 2012, 26, 1344-1352.

(63) Boronat, M.; Corma, A. Are carbenium and carbonium ions reaction intermediates in zeolite-catalyzed reactions? Appl. Catal., A 2008, 336, 2-10.

(64) Fang, H.; Zheng, A.; Xu, J.; Li, S.; Chu, Y.; Chen, L.; Deng, F. Theoretical Investigation of the Effects of the Zeolite Framework on the Stability of Carbenium Ions. J. Phys. Chem. C 2011, 115, 7429-7439. 